Highlights

\title{
SOME GUIDELINES FOR WRITING A LETTER TO THE EDITOR
}

\author{
Zorica Antić \\ Faculty of Medicine, University of Niš, Niš, Serbia
}

\begin{abstract}
Letter to the editor is a tool offered to readers most often to react to articles published in a journal. From the standpoint of journals, this genre is very important as it prolongs the process of peer review and maintains the integrity of evidence. These letters have a specific structure often determined by the journals in terms of the number of words, authors, references, figures, and tables. With regard to the style, letters to the editor should be clear, precise and to the point, stating the purpose directly and avoiding unnecessary information. Compared to research articles, letters to the editor rarely use passive constructions and hedging, the most commonly used tense is the present simple and they are often laden with nouns and verbs belonging to the critical style and reflecting strong subjectivity. Although a tool for questioning previously validated research, letters to the editor need to be written in a respectful manner, maintaining the professional level of communication and always having in mind that the purpose is sharing and promotion of knowledge.
\end{abstract}

Key words: letter to the editor, writing skill, structure, style, grammar.

\section{Introduction}

Discussion and exchange of ideas are fundamental to scientific research and progress. Letters to the editor can form an important aspect of the development of such ideas. They enable free expression of opinion, reveal the intellectual vigor of the community concerned, and help shape knowledge [1].

Scientific discourse occurs in many forms - among colleagues, at scientific meetings, during peer review, and after publication. Such discourse is essential to interpreting studies and guiding future research. Letter to the editor is a written way of talking to a journal, newspaper or other regularly printed publication. It is found in the first section of the journal or in the editorial page. For journals, these letters are very important [2]. They serve an important role in post-publication review by maintaining the integrity of evidence. The act of critical appraisal of the literature, an important step of evidence-based practice, may generate letters to the editor. Letters may serve to (1) identify errors or deficiencies and make a correction to the literature, (2) point out alternative theories or additional information not contained in the original article, (3) offer new, additional, or counterevidence to that of the original article, and/or (4) hold authors and journals accountable for their publications [2, 3].

The most frequent reason for writing a letter to the editor is to comment on a published article. Its purpose is to support or criticize the justification, analysis or outcome of the study. The letter should point out to

Correspondence to: Zorica Antić, Ph.D

Faculty of Medicine, 81 Zoran Đinđić Blvd., 18000 Niš, Serbia

Phone: +381691045494

E-mail: englishformedicine@gmail.com

Received May 20 ${ }^{\text {th }}, 2019$, Accepted June $23^{\text {rd }}, 2018$ new, not previously considered issues, and represent additional information which refute or support the assertions of other authors. The author of the letter should avoid assuming a personal and biased attitude but base all his suggestions and comments on scientific data and evidence. The criticism should be professional. The letter should contain objective, constructive interpretation or discussions on the area of interest. It should have an objective and transmit a message with brief, clear language. Materials published elsewhere should not be used [4].

In general, letter to the editor should be concise and to the point. The author ties the subject of the letter to a recent article and uses this article for communicating a message. As one of the widely read features in journals, these letters allow an author to reach a wide audience.

\section{Letter to the Editor in Medical Journals}

Among the genres identified in medical journals, along with research papers, review articles, editorials, book reviews, case studies, and the news section, letters to the editor are a tool offered to the community to react to other scientists' research and mainly to express personal opinions and disagreement. Letters to the editor offer a freer mode of expression than the classical scientific rhetoric, which is described as objective, purely referential, impersonal, and detached [5].

From mere clarifications aiming to provide further knowledge on a given research topic, letters to the editor gradually became a tool for questioning previously validated research. They have grown as a complementary, and sometimes alternative strategy used to establish a position, and defend it in the scientific community. 
Letters to the editor are a way to express one's opinion or to set something straight but they are not really letters, communication actually builds up between a scientist and his or her community and not between two individuals.

Letters to the editor usually represent a form of contradiction of the research paper. Controversy generally concerns the experimental method selected, the duration of the experiment, the number of experimental subjects, and results too flimsy or too frail to be exploited.

The letter writers require the entire community to witness and even take part in their public debate. Writing letters to the editor may appear to be an irrepressible need for some scientists because it allows them to react swiftly, personally, and sometimes contentiously to issues about which they feel strongly concerned [4].

\section{The Structure and Style of Letters to the Editor}

First of all, as with any other piece of writing, a journal may set certain limitations concerning the length of the letter, the number of authors, the number of figures and/or tables, the number of references.

An interesting point is the very low occurrence of passive structures in letters to the editor. Scientific discourse is generally characterized by a heavy use of the passive, especially in the 'Materials and Methods' and the 'Results' sections of papers. The reason for this is to focus on the object of the experiment, rather than on the subject, to give an objective value to the published research. In letters to the editor, on the contrary, the emphasis is put on the choices made by the criticized authors and thereby on the authors of the letters themselves. Thus, selecting active forms to build an argument strongly reinforces the contentious mode [6].

The most common grammatical tense used is the simple present tense, and this again contrasts sharply with the research article, in which majority of the verbs are in the simple past. In letters to the editor, the simple past is used only to report the experiments carried out by the criticized authors or by the authors themselves. The simple present is chosen to express the reality of the article in question and it refers to the established scientific fact.

Scientific discourse is generally used to weigh evidence and draw conclusions from data. Thus, uncertainty and doubt are necessarily present at least in the 'Discussion' section of experimental papers. This is expressed through hedges, which account for various degrees of probability. Scientific discourse deals with the problem of what is true or false. In letters to the editor, in contrast, epistemic modality (hedging) has a low occurrence. The most frequently used modals are should, could, may, and would and to a lesser extent can, must, will, and might.

In contrast to epistemic modals, root modals may convey a deontic meaning to indicate a form of moral advice, expressing strong pressure from the utterer on the criticized authors. Root modals serve to express orders, wishes, suggestions, causality, or capacity [4].

In contrast to the depersonalized style observed in the experimental paper, giving vent to direct criticism in letters to the editor is accepted by the community. Some of the commonly used terms include poorly, mistakenly, biased, emotive, confusing, too simplistic, old and outmoded, artificial, vague, speculative.

Letters also reveal a massive use of certain nouns and verbs that are absent from the research paper because they belong to the critical style and reflect strong subjectivity. Nouns such as critique, rebuttal, borderline, reductionism and blurring and verbs such as refute, rebut, fail to, contend, disagree, reject, challenge and invalidate are common in letters.

In scientific discourse, adjectives mostly express a quantitative value, whereas in letters to the editor, an extensive use of qualitative adjectives can be observed. Most of them carry a negative prefix whose aim to weaken the arguments set out in the paper. Examples of these prefixes are in- (inappropriate, inaccurate, inconsistent, incomplete, intemperate, incorrect, implausible, etc.), un- (unreliable, unexpected, unproven, unsupported, unclear, unaware, unfounded, unfortunate, etc.), out- (outmoded, etc.), under- (underpowered, understated, etc.) and mis- (misleading, misused, misdirected, etc.).

Specific markers are necessary to build an argument. In letters to the editor, these markers may be classified into four groups that all express disagreement but with different levels of intensity.

Concession - The weakest markers used to contradict somebody's opinion express concession. The most recurrent forms present in letters to the editor are although, however, but, yet, nevertheless, nonetheless, even if, even though. These markers are used to diminish or belittle the impact of published observations and conclusions.

Antithesis - In order to express the opposition in a stronger way, the following markers can be used: but, while, whereas, conversely, by contrast, in contrast, otherwise, instead, unlike, opposite.

Rewording - Some markers are used to reformulate a previous statement and incite the criticized authors to change their minds and possibly their methods or conclusions. Examples of these markers are rather, better, more accurately, in other words.

Doubt - The most subtle way of explicitly questioning a method is to raise doubts concerning the validity of the study. The most common words and expressions used in letters to the editor to mark this are maybe, perhaps, probably, highly unlikely, wonder whether, far from verified.

The use of implicit disagreement can be considered to be a less direct way to modulate contradiction. Examples of these forms are: we find it surprising that, therefore we strongly suggest, therefore we think, I have several comments, I showed clearly, In my opinion, we believe, we are aware, we advocate doing this. 
Letters to the editor are a useful, and even necessary, but not self-sufficient communication tool within the scientific community. They reflect tensions in this community. Their most interesting role is to provide researchers with an outlet for oppositions, controversies, and disagreements [5].
Table 1 shows an example of a letter to the editor published in a scientific journal.

Table 1 Example letter to the editor.

\section{FALLS AND MOBILITY LIMITATIONS IN OLDER PEOPLE: MEASURES OF HIGHER CEREBRAL INTEGRATION ARE ALSO IMPORTANT}

To the Editor:

Ferrucci et al draw welcome attention to the importance of undiagnosed and subtle manifestations of neurological disease in older people (1). However, the authors fail to include two common neurological findings that are possibly as important, if not more so, than the individual signs that they describe. The detection of cognitive impairment by formal cognitive screening is a neurological finding in its own right. The very act of excluding 104 patients with cognitive impairment short of dementia ( $8 \%$ of the study sample) may have diluted the predictive power of their study. Cognitive impairment is a potent risk factor for gait imbalance and falls (2) and is often undetected in routine clinical practice (3). Although the reason for exclusion relates to the use of subject recall as an index of falls over the previous 12 months, it would be helpful for further studies to include older people with cognitive impairment that falls short of overt dementia. An equally important neurological finding that is not included in the study is that of higher-level gait disorders or gait apraxia (4). These conditions have been characterized very well by Tallis and coworkers as a disorder of gait that is out of proportion to what would be expected on bedside neurological examination and is best explained by disorders of integration of cerebral activity (5). There is a reasonably high level of inter-rater reliability in detection of this finding between experienced doctors and physiotherapists (6). It is likely that the key cause in gait apraxia is silent and overt cerebrovascular disease. While Ferrucci et al suggest that radiological changes in white matter may be associated with the findings described in their study, it is even more likely that the changes are associated with gait apraxia in older people (7). In addition, many patients with subtle, undetected signs of upper motor neuron lesions (positive Babinski/Hoffman reflexes or increased tendon reflexes) may also have demonstrated gait apraxia. Conversely, could some of the 68 subjects with a history of falling and "no" neurological findings have had an element of gait apraxia?

The emphasis on careful neurological history and examination for older people with impairment of stability and mobility is welcome. However, it is important that it should routinely include measures of higher cerebral integrationin particular, cognitive function and assessment of gait apraxia.

Sean Kennelly, MB, BCh, BAO, MRCPI

Professor Desmond O’Neill, MD Department of Medical Gerontology Trinity Center for Health Sciences Adelaide and Meath Hospital Dublin, Ireland

1. Ferrucci L, Bandinelli S, Cavazzini C, et al. Neurological examination findings to predict limitations in mobility and falls in older persons without a history of neurological disease. Am J Med. 2004;116:807-815.

2. Tinetti ME, Speechley M, Ginter SF. Risk factors for falls among elderly persons living in the community. N Engl J Med. 1988;319: 1701-1707.

3. Goldschmidt TJ, Mallin R, Still CN. Recognition of cognitive impairment in primary care outpatients. South Med J. 1983;76: 1264-1265, 1270.

4. Martin MP, O’Neill D. Vascular higherlevel gait disorders-a step in the right direction? Lancet. 2004;363:8.

5. Liston R, Mickelborough J, Bene J, et al. A new classification of higher level gait disorders in patients with cerebral multi-infarct states. Age and Aging. 2003;32:252-258.

6. Griffin E, Martin M, O’Neill D. Gait abnormality in a day hospital - comparison of inter- professional assessment. Ir J Med Sci. 2003;172:3.

7. Benson RR, Guttmann CRG, Wei X, et al. Older people with impaired mobility have specific loci of periventricular abnormality on MRI. Neurology. 2002;58:48 -55. 
After opening the letter, the next step is to grab the readers' attention by stating the reason for writing. The key point is given at the beginning and the importance of the issue is explained. This is immediately followed by stating the evidence for praise or criticism (Table 2). Good practice is to give suggestions about what could be done differently with better results.

Table 2 The opening paragraph illustrating the steps for starting a letter to the editor.

\section{To the Editor:}

Leung et all present a 10-year study of patients taking antihypertensives followed for hyponatremia. Their study is an important contribution to the literature on the comparative effectiveness of commonly used hypertensives. We are concerned, however, with 2 aspects of their design, both of which may induce selection bias with the potential to explain their observed results.

*The American Journal of Medicine, December 2012 Volume 125, Issue 12, p. e7. [8]

Some of the useful expressions for writing a letter to the editor are presented in Table 3.

Beside maintaining the clarity and precision in writing a letter to the editor, another very important thing that the author should keep in mind is the need for presenting the ideas and the point of view in a respectful manner, not using the letter simply to "vent". The comments should be objective and they should critically assess the published article, offering scholarly opinion and information relevant to the readers [9].

\section{Conclusion}

One of the purposes of letters to the editor is allowing the readers of a journal to comment on recently pub-

\section{References}

1. Gotti, M. (2003). Specialized discourse: Linguistic features and changing conventions. Bern: Peter Lang.

2. Roman, K., \& Raphaelson, J. (1992) Writing that works. New York, NY: Harper-Collins, 1992.

3. Seekins, T., \& Fawcett. S. (1984). A Guide to writing letters to the editor: Expressing your opinion to the public effectively. Lawrence, KS: Research and Training Center on Independent Living, University of Kansas.

4. Swales J M (1990). Genre analysis. English in academic and research settings. Cambridge: Cambridge University Press.
Table 3 Some expressions commonly used in letters to the editor.

\begin{tabular}{|c|c|}
\hline $\begin{array}{l}\text { To begin the letter: } \\
\text { - I have read with great } \\
\text { interest ... } \\
\text { - I am writing to express } \\
\text { my support for / } \\
\text { (dis)approval of ... } \\
\text { - I am writing with } \\
\text { regard to ... } \\
\text { - I am writing about ... }\end{array}$ & $\begin{array}{l}\text { To state an opinion: } \\
\text { - In my opinion... } \\
\text { - I do not believe that ... } \\
\text { - I strongly (dis)agree } \\
\text { with ... } \\
\text { - I am opposed to ... } \\
\text { - I am in favor of ... }\end{array}$ \\
\hline $\begin{array}{l}\text { To express consequences / } \\
\text { results: } \\
\text { - Therefore, ... } \\
\text { - As a result ,... } \\
\text { - Consequently, ... } \\
\text { - Obviously, ... } \\
\text { - Clearly, ... }\end{array}$ & $\begin{array}{l}\text { To list points: } \\
\text { - Firstly, .. } \\
\text { - First of all, .. } \\
\text { - Secondly, ... } \\
\text { - Furthermore, } \ldots \\
\text { - Finally, ... }\end{array}$ \\
\hline
\end{tabular}

lished articles. These letters may ask important questions of the author of published papers, request clarification about the content, request additional data, provide an alternative viewpoint or criticize [9].

The letter to the editor is important as it allows the peer review process to continue after an article is published. In that way, the authors are held accountable for the content of articles.

Journals typically have instructions for writing a letter to the editor in terms of limits on the number of words, references, tables, figures in a letter.

The writer should focus on the reason for writing, avoiding unnecessary information, assuring the statements are accurate, objective and supported by appropriate arguments and references. Furthermore, even though the purpose of the letter may be criticism, it is imperative to maintain professionalism in communicating ideas and opinions.

5. Webber P (2002). 'From spoken science to published research article: A comparative case study.' In Banks D (ed.) Text and texture. Paris: L'Harmattan. 571-596.

6. Hyland, K. (2000). Disciplinary discourses: Social interactions in academic writing. London: Longman.

7. The American Journal of Medicine, December 15, 2004 Volume 117, Issue 12, p. 971.

8. The American Journal of Medicine, December 2012 Volume 125 , Issue 12 , p. e7.

9. Nunan D. (Ed.) (2003). Practical English language teaching. New York: McGraw-Hill Contemporary. 